ReviewArticle

\title{
Angiotensin-Converting Enzyme Inhibitor / Angiotensin II Receptor Blocker in COVID-19: a Double-edged Sword or a Myth
}

\author{
Kunal Bikram Shaha', Ashok Adhikari ${ }^{1}$, Jung Rae Cho ${ }^{2}$, Bimal Pandey33, Yuba Raj \\ Sharma ${ }^{4}$ Md.Sajjad Safi
}

${ }^{1}$ Department of Internal medicine, Cardiology, Patan Academy of Health Sciences, Lalitpur, Nepal ${ }^{2}$ Department of Cardiology, Kangnam Sacred Heart Hospital, HUMC, South Korea

${ }^{3}$ Department of Internal medicine, Nephrology, Patan Academy of Health Sciences, Lalitpur, Nepal

${ }^{4}$ Department of Internal medicine, Patan Academy of Health Sciences, Lalitpur, Nepal

\section{ABSTRACT}

\begin{abstract}
Angiotensin-converting enzyme-2 receptor has been unearthed as a prime site of entry of Severe Acute Respiratory Syndrome Coronavirus 2 owing to its strong affinity towards spike protein of Severe Acute Respiratory Syndrome Coronavirus 2, resulting in down-regulation of Angiotensinconverting enzyme -2 receptors and hyperstimulation of Angiotensin-converting enzyme-1 pathway. This proposed theory has led to the birth of a new controversy regarding the use of Angiotensinconverting enzyme inhibitors/angiotensin receptor blockers in Coronavirus disease 2019 patients. A theory is against the use of Angiotensin-converting enzyme inhibitors/angiotensin receptor blockers, as it enhances the effect of Angiotensin-converting enzyme -2 pathway and upregulation of Angiotensin-converting enzyme -2 receptors resulting in a large number of internalizations of Severe Acute Respiratory Syndrome Coronavirus -2 into cells culminating into a high load of viremia with overwhelming infection and severity. The other theory considers Angiotensin-converting enzyme inhibitors / Angiotensin receptor blockers useful as it blocks deleterious Angiotensin-converting enzyme -1 pathway triggered by Severe Acute Respiratory Syndrome Coronavirus 2 and enhances Angiotensin-converting enzyme -2 receptor upregulation and activation of angiotensin-(1-7) leading to beneficial effects, i.e vasodilation, anti-apoptosis, anti-proliferative, \& antifibrosis. Hence, Angiotensin-converting enzyme inhibitors/angiotensin receptor blockers may prove beneficial in countering the Angiotensin-converting enzyme -1 mediated damage by Severe Acute Respiratory Syndrome Coronavirus 2. The recommendations by (European \& American) societal guidelines still hold good of not discontinuing Angiotensin-converting enzyme inhibitors/angiotensin receptor blockers in COVID-19 patients as it is further supported by current evidence of large observational studies.
\end{abstract}

Keywords: Acute respiratory syndrome; Angiotensin-converting enzyme; Angiotensin II receptor;

Blocker, Coronavirus; COVID-19; Inhibitor

\section{Correspondence:}

Dr. Kunal Bikram Shaha, MBBS, FCPS, FACC

Assistant Professor, Department of Internal medicine, Cardiology, Patan Academy of Health Sciences, Lalitpur, Nepal ORCID ID: 0000-0002-1220-7872

Email: drshahakunal19@gmail.com

Submitted: $5^{\text {th }}$ May 2020 Accepted: $23^{\text {rd }}$ May 2020

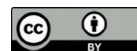

Source of support: None

Conflict of Interest: None

Citation: Shaha KB, Adhikari A, Cho JR, Pandey B, Sharma YR, Safi MS. Angiotensin-converting enzyme inhibitor and angiotensin ii receptor blocker in COVID-19: a double-edged sword or a myth. NMJ 2020;3(1):309-12. DOI· $10.3126 / \mathrm{nmj} . v 3 \mathrm{il} .28726$

\section{INTRODUCTION}

Coronavirus disease 2019 (COVID-19) is caused by severe acute respiratory syndrome coronavirus 2 (SARS-CoV-2) or 2019 novel coronavirus as per nomenclature by the World Health Organization. Angiotensin-converting enzyme-2 (ACE-2) receptor abundance in heart ${ }^{1}$ explains the cardiotropic behaviour of SARS-CoV-2 which helps virus internalization into the host cells. ACE-2 receptor has a strong binding affinity to the surface spike protein of SARS-Cov- $2^{2}$ (fig. 1A). The complex of spike protein and ACE-2 receptor after binding is proteolytically processed by type 2 transmembrane protease (TMPRSS2) leading to cleavage of ACE-2 receptor and activation of the spike protein ${ }^{3,4,5,6}$ (fig. 1B) and thus viral genome internalizes into cells (fig. 1C). ${ }^{6}$ It has been suggested that cells in which ACE-2 receptor and TMPRSS2 are simultaneously present are most susceptible to entry by SARS-CoV. ${ }^{5}$ 

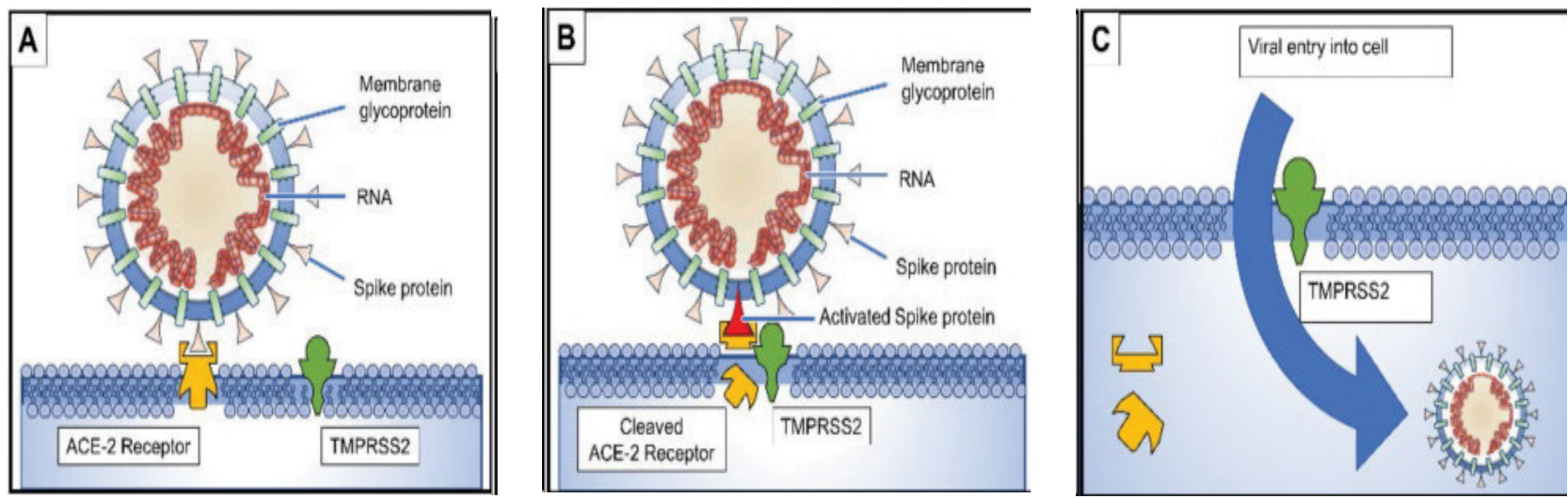

Figure 1: Three-step SARS-Cov-2 virus internalization in a host cell; Source: Rabi FA et al. Pathogens 2020

\section{COVID-19 AND THE HEART DISEASE}

Putative mechanism of acute cardiac injury in COVID-19 as described in figure 2, involves direct cardiotropic myocardial injury, Angiotensinconverting enzyme (ACE) mediated damage by SARS-CoV-2, cytokine storm or dysregulation resulting in systemic inflammatory response syndrome, microvascular dysfunction and damage as a result of disseminated intravascular coagulation. ${ }^{7-13}$

The acute cardiac injury was noted significantly in COVID-19 patients

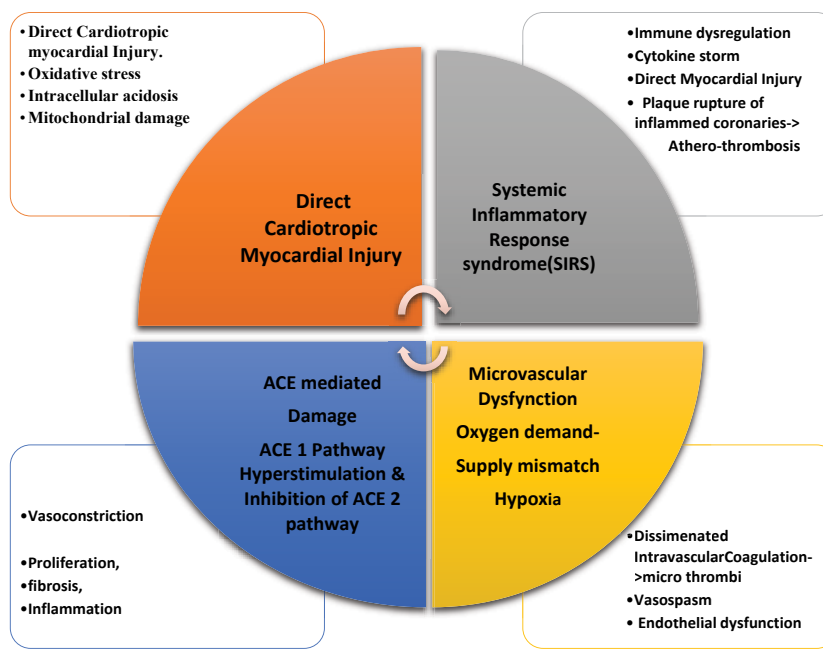

Figure 2: Wagon wheel of pathophysiology in acute cardiac injury by SARS-CoV-2

having preexisting cardiovascular diseases. Approximately 30\% and $60 \%$ of patients with cardiac injury had a history of coronary heart disease and hypertension, respectively. ${ }^{14}$ This depicts the burden of acute cardiac injury in patients with the cardiovascular disorder because of the abundance of existing renin-angiotensin-aldosterone system (RAAS) activation which is further accelerated by ACE mediated SARS-CoV-2 damage.

According to the "Diagnosis and Treatment of Novel Coronavirus Pneumonia (Trial Version 4) ${ }^{15}$," elderly patients with underlying diseases are more likely to be infected with SARS-CoV-2 and tend to be severely ill, especially those with hypertension, coronary heart disease, and diabetes.

The high prevalence of hypertension and cardiovascular disorder in COVID-19 and its impact on case fatality rate has (Table 1) brought the debate of usage of commonly used antihypertensive drug
Angiotensin-Converting Enzyme Inhibitor (ACEI), or Angiotensin II Receptor Blocker (ARB) into the limelight in COVID-19 patients.

Table 1: Prevalence and case fatality rate in COVID-19 from a meta-analysis of six published studies from China $^{16,17}$

\begin{tabular}{|l|l|l|}
\hline Prevalence & Underlying disease & Case fatality rate (CFR) \\
\hline $9.7 \%$ & Diabetes & $7.3 \%$ \\
\hline $16.4 \%$ & $\begin{array}{l}\text { Cardio- } \\
\text { cerebrovascular } \\
\text { Disease }\end{array}$ & $10.5 \%$ \\
\hline $17.1 \%$ & Hypertension & $6 \%$ \\
\hline
\end{tabular}

\section{EFFECT OF COVID-19 ON RAAS SYSTEM}

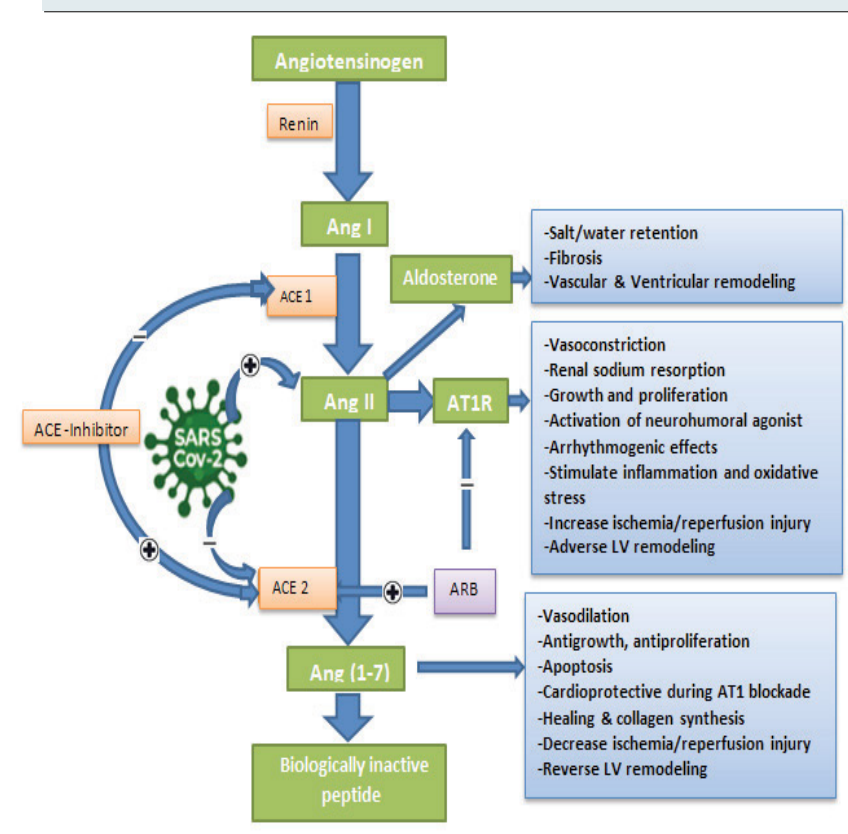

Figure 3: ACE mediated damage by SARS-CoV-2. (ACE1, Angiotensin-converting enzyme 1; ACE-2, Angiotensinconverting enzyme 2; Ang I, angiotensin I; AT1R, angiotensin II type 1 receptor) 
As per Guo J et al. ${ }^{13}$, SARS-CoV-2 utilizes the ACE-2 receptors to get internalized into the cells. Hence, there is paucity/downregulation of ACE-2 receptors resulting in enhancement of ACE-1 pathway fetching deleterious effect of RAAS system (fig.3), i.e vasoconstriction, inflammation, fibrosis, and proliferation promoting hypertension, cardiac fibrosis, thrombosis, and acute respiratory distress syndrome(ARDS) /acute lung injury. ${ }^{13,18}$

\section{RAAS NEGATIVE EFFECT THEORY HYPOTHESIS}

The use of ACEI/ARB will block the ACE-1 pathway and enhance the effect of ACE-2 pathway and up-regulation of ACE-2 receptors ${ }^{13}$, resulting in a large number of internalization of COVID-19 into cells culminating into a high load of viremia with overwhelming infection and severity. (fig.4) Hence, starting RAAS blockers i.e ACEI/ARB as an anti-hypertensive only may not be a good choice without other compelling mortality reducing indication of ACEI/ARB if the patient is not yet on ACEI/ARB. In that case, starting another group of antihypertensive may be beneficial before contracting COVID-19.

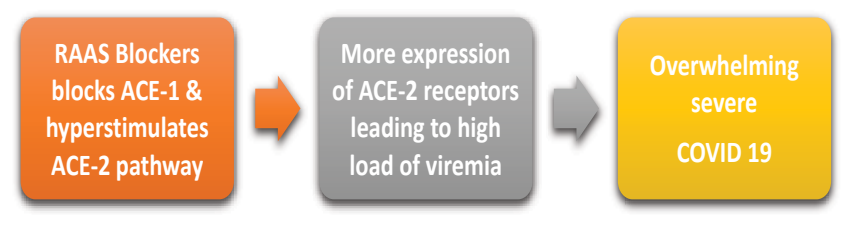

Figure 4: Deleterious Effect of RAAS blockers on COVID 19.

\section{RAAS POSITIVE EFFECT THEORY HYPOTHESIS}

ACEI/ARB blocks deleterious ACE-1 pathway triggered by COVID-19 and enhances ACE-2 receptor upregulation ${ }^{18}$ and activation of angiotensin-(1-7) leading to beneficial effects i.e vasodilation, anti-apoptosis, anti-proliferative $\&$ antifibrosis ${ }^{13}$ (fig.3), may prove beneficial in countering the ACE-1 receptor-mediated damage by COVID-19. (fig. 5) Hence, once the patient has contracted COVID-19, the initiation of ACEI/ARB may be beneficial in curbing down the ACE-1 receptor-mediated damage just at the cost of more internalization of the virus by upregulating ACE- 2 receptors.

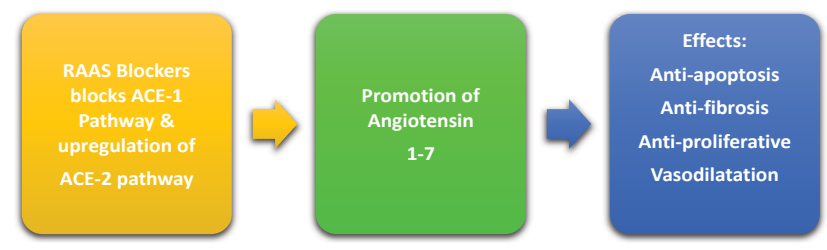

Figure 5:Beneficial Effect of RAAS blockers on COVID-19

\section{CURRENT EVIDENCE}

It is a topic of debate, whether the RAAS positive or negative effect theory will prove it's validity based on a clinical trial. A recent study by Zhang P et al. ${ }^{19}$ showed that inpatient use of ACEI/ARB was associated with a lower risk of all-cause mortality compared with ACEI/ARB non-users. This study being an observational study poses potential residual confounders. Despite this fact it is unlikely that in-hospital use of ACEI/ARB was associated with increased mortality risk.

Another pertinent study by Li $\mathrm{J}$ et al. ${ }^{20}$ from Wuhan evaluated 362 patients with hypertension out of a case series study of 1178 hospitalized COVID-19 patients regarding the association of RAAS inhibitors with the severity of disease or risk of death. The in-hospital mortality in patients with hypertension was $21.3 \%$. The percentage of patients with hypertension taking ACEI/ARB did not differ between those with severe and nonsevere infections $(32.9 \%$ vs $30.7 \% ; p=.645)$ nor did it differ between nonsurvivors and survivors (27.3\% vs $33.0 \%$; $p=.34$ ) suggesting ACEI/ARB are not associated with the severity or mortality of COVID-19 in such patients.

An Italian case-control study by Mancia et al. ${ }^{21}$ from Lombardy compared 6272 people with confirmed SARS-CoV-2 infection that were diagnosed between February 21 and March 11, 2020, with 30,759 controls who were matched according to age, sex, and the municipality of residence. The logistic regression analysis of this study after adjustment of confounder revealed neither ACEI / ARB was associated with the increased likelihood of SARS-CoV-2 infection nor any association between these drugs and severe COVID-19. ${ }^{21}$

Reynolds et al. ${ }^{22}$ using data from the electronic health records of 12,594 patients in New York University assessed the relation between previous treatment with different classes of antihypertensives (ACEI/ ARB, beta-blockers, calcium-channel blockers, or thiazide diuretics) and the likelihood of contracting SARS-CoV-2. Additionally it assessed the relation between antihypertensive and worsening severity of COVID-19. Using Bayesian methods, after propensityscore matching for receipt of each medication class, neither a single medication class including ACEI/ARB showed any association with an increase in the likelihood of a positive test nor did they show any substantial increase in the risk of severe illness among patients who tested positive ensuring safety of ACEI/ARB in COVID-19.22

Mehra et al. ${ }^{23}$ using an observational database from 169 hospitals in Asia, Europe, and North America, evaluated the relationship of cardiovascular disease and drug therapy with in-hospital death among hospitalized 8910 patients with COVID-19 who were admitted between December 20, 2019, and March 15, 2020, and who had either died in the hospital or survived to hospital discharge. The multivariate logistic regression analysis of this study revealed an increased risk of in-hospital death in patients with age greater than 65 years, coronary artery disease, congestive heart failure, history of cardiac arrhythmia, chronic obstructive pulmonary disease, and current smoking status. On the contrary, female sex was associated with a decreased risk. Neither of the RAAS blockers i.e ACEI/ARB was associated with an increased risk of in-hospital death. A secondary analysis that was restricted to patients with hypertension with a compelling indication of ACEI/ARB revealed no harm. ${ }^{24}$

\section{FUTURE DIRECTIVES ON RECOMBINANT HUMAN ACE-2}

The recombinant human ACE-2 (rhACE-2) is purified from the supernatant of ACE-2 transfected cells. The rhACE-2 protein has been shown to relieve lung injuries in several acute pneumonia experimental models. Additionally it prevents angiotensin II-induced hypertension, myocardial hypertrophy, diastolic dysfunction, and myocardial fibrosis ${ }^{13}$ and has been proposed to be cardio-protective. Apart from these roles, rhACE-2 may act as a protein molecule that can neutralize the spike protein of SARS-CoV-2 and thus can prevent from contracting COVID-19. More evidence from laboratory and clinical future research is needed for establishing rhACE-2 as a potential therapeutic option in COVID-19. ${ }^{13}$

\section{DISCUSSION}

Considering two first pertinent studies by Zhang P et al. ${ }^{19}$, Li J et al ${ }^{20}$., the recommendation by (European ${ }^{25} \&$ American $^{26}$ ) Societal guidelines still holds good of not discontinuing ACEI/ARB in COVID-19 patients despite having different results from either study. A common inference can be drawn that ACEI/ARB does not harm COVID-19 patients.

Amidst various postulations of RAAS positive \& negative effect theory, Mancia et al. ${ }^{21}$ revealed that ACEI/ARB did not affect the risk of contracting COVID-19. In continuation of the same preaching, 
Reynold et $\mathrm{al}^{22}$ showed no positive association of any of the analyzed drug classes, including ACE inhibitors and ARB, with SARS-Cov 2 positivity and worsening of the severe illness of COVID-1924. Mehra et al. ${ }^{23}$ showed neither of the RAAS blockers i.e ACEI/ARB was associated with an increased risk of in-hospital death. A secondary analysis that was restricted to patients with hypertension with a compelling indication of RAAS blockers revealed no harm. ${ }^{24}$ Hence, a clear message of the safety of ACEI/ARB usage in COVID-19 patients has finally emerged.

A further extrapolation of findings of Zhang et al. and Mehra et al suggests that ACEI/ARB even lowers the risk of all-cause mortality and in-hospital mortality, respectively. The disparity in results may point to the need for randomized controlled trials to emblem this fact.
Though all are observational studies with limitations of few possible confounders but still represent a variety of populations from different parts of the world with a common answer unveiling the final truth that the "RAAS blocker are safe in COVID-19". rhACE 2 has some promising future perspective in terms of prevention and treatment of COVID-19 emphasizing ACE mediated damage by SARS-CoV-2 though yet to be proven in human clinical trials.

\section{CONCLUSIONS}

Current evidence-based medicine has thus busted the myth that ACEI/ ARB is not a double-edged sword rather a safe and therapeutic coprescription in COVID-19 patients.

\section{REFERENCES}

1. Zou X, Chen K, Zou J, Han P, Hao J, Han Z. Single-cell RNA-seq data analysis on the receptor ACE2 expression reveals the potential risk of different human organs vulnerable to $2019-\mathrm{nCoV}$ infection. Front Med 2020. Crossref

2. Wrapp D, Wang N, Corbett KS, Goldsmith JA, Hsieh CL, Abiona $\mathrm{O}$ et al. Cryo-EM structure of the 2019-nCoV spike in the prefusion conformation. Science. 2020;367(6483):1260-3. $\underline{\text { Crossref }}$

3. Glowacka, I, Bertram S, Muller MA, Allen P, Soilleux E, Pfefffferle S et al. Evidence that TMPRSS2 Activates the Severe Acute Respiratory Syndrome Coronavirus Spike Protein for Membrane Fusion and Reduces Viral Control by the Humoral Immune Response. Virol. 2011;85:412234. $\underline{\text { Crossref }}$

4. Heurich, A, Hofmann-Winkler H, Gierer S, Liepold T, Jahn, O.; Pohlmann, S. TMPRSS2 and ADAM17 Cleave ACE2 Diffferentially and Only Proteolysis by TMPRSS2 Augments Entry Driven by the Severe Acute Respiratory Syndrome Coronavirus Spike Protein. J. Virol. 2014;88:1293-1307. Website

5. Shulla A, Heald-Sargent T, Subramanya G, Zhao J, Perlman, S, Gallagher T. A Transmembrane Serine Protease Is Linked to the Severe Acute Respiratory Syndrome Coronavirus Receptor and Activates Virus Entry. J. Virol. 2011;85:873-82. Crossref

6. Rabi FA, Al Zoubi MS, Kasasbeh GA, Salameh DM, Al-Nasser AD. SARS-CoV-2 and Coronavirus Disease 2019: What We Know So Far. Pathogens. 2020;9(3):231. $\underline{\text { Crossref }}$

7. Clerkin KJ, Fried JA, Raikhelkar J, Sayer G, Grii n JM, Masoumi A et al. Coronavirus Disease 2019 (COVID-19) and Cardiovascular Disease. Circulation. 2020. Crossref

8. Chen Y, Li Y, Liu X. Potential pathophysiological mechanisms underlying COVID-19-induced myocardial injury[J]. Chin J Pathophysiol. 2020;36(3):573-6. $\underline{\text { Crossref }}$

9. Hendren NS, Drazner MH, Bozkurt B, et al. Acute COVID-19 Cardiovascular Syndrome. Circulation. 2020. Crossref

10. Murphy SP, Kakkar R, Mc Carthy CP, Januzzi JL Jr. Inflammation in Heart Failure. J Am Coll Cardio. 2020;75(11):1324-40. Crossref

11. Wang D, Hu B, Hu C, Zhu F, Liu X, Zhang J, et al. Clinical Characteristics of 138 Hospitalized Patients With 2019 Novel Coronavirus-Infected Pneumonia in Wuhan, China. JAMA. 2020;323(11):1061-9. Crossref

12. Musher DM, Abers MS, Corrales VF, Medina C, et al. Acute Infection and Myocardial Infarction. N Engl J Med. 2019;380:171-6. Crossref

13. Guo J, Huang Z, Lin L, Lv J. Coronavirus Disease 2019 (COVID-19) and Cardiovascular Disease: A Viewpoint on the Potential Influence of Angiotensin-Converting Enzyme Inhibitors/Angiotensin Receptor Blockers on Onset and Severity of Severe Acute Respiratory Syndrome
Coronavirus 2 Infection. J Am Heart Assoc. 2020. $\underline{\text { Crossref }}$

14. Shi S, Qin M, Shen B, Cai Y, Liu T, Yang F, et al. Association of Cardiac Injury With Mortality in Hospitalized Patients With COVID-19 in Wuhan, China. JAMA Cardiol. 2020. Crossref

15. Diagnosis and treatment of pneumonia caused by novel coronavirus (trial version 4). In Chinese. [online] 2020 [Cited 2020 April 2] Available from: Website

16. Wu Z, McGoogan JM. Characteristics of and Important Lessons From the Coronavirus Disease 2019 (COVID-19) Outbreak in China: Summary of a Report of 72314 Cases From the Chinese Center for Disease Control and Prevention. JAMA. 2020;323(13):1239-42. Crossref

17. Li B, Yang J, Zhao F, Zhi L, Wang X, Liiu L, et al. Prevalence and impact of cardiovascular metabolic diseases on COVID-19 in China. Clin Res Cardiol. 2020;109(5):531-8. $\underline{\text { Crossref }}$

18. Kuba K, Imai Y, Rao S, Gao H, Guo F, Guan B, et al. A crucial role of angiotensin-converting enzyme 2 (ACE2) in SARS coronavirus-induced lung injury. Nat Med. 2005;11(8):875-9. Crossref

19. 'Zhang P, Zhu L, Cai J, Lei F, Qin JJ, Xie J, et al. Association of Inpatient Use of Angiotensin Converting Enzyme Inhibitors and Angiotensin II Receptor Blockers with Mortality Among Patients With Hypertension Hospitalized With COVID-19 Circ Res. 2020. Crossref

20. Li J, Wang X, Chen J, Zhang H, Deng A. Association of renin-angiotensin system inhibitors with severity or risk of death in patients with hypertension hospitalized for coronavirus disease 2019 (COVID-19) infection in Wuhan, China. JAMA Cardiol. 2020. $\underline{\text { Crossref }}$

21. Mancia G, Rea F, Ludergnani M, Apolone G, Corrao G. Reninangiotensin- aldosterone system blockers and the risk of Covid-19. N Engl J Med. 2020. Crossref

22. Reynolds HR, Adhikari S, Pulgarin C, Troxel AB, Iturrate E, Johnson $\mathrm{SB}$, et al. Renin-angiotensin-aldosterone system inhibitors and risk of Covid-19. N Engl J Med. 2020. Crossref

23. Mehra MR, Desai SS, Kuy S, Henry TD, Patel AN. Cardiovascular disease, drug therapy, and mortality in Covid-19. N Engl J Med. 2020. Crossref

24. Jarcho JA, Ingelfinger JR, Hamel MB, D'Agostino RB, Harrington, DP. Inhibitors of the renin-angiotensin-aldosterone system and Covid-19. N Eng J Med. 2020. Crossref

25. Position statement of the ESC Council on Hypertension on ACEinhibitors and angiotensin receptor blockers. [online] 2020 (cited 2020 May 2) Available from: Website

26. HFSA/ACC/AHA statement addresses concerns re: using RAAS antagonists in COVID-19[online] 2020 (cited 2020 May 2)Available from: Website 